\title{
Mechanistic insights into ozone-initiated oxidative degradation of saturated hydrocarbons and polymers
}

\author{
Richmond Lee, Michelle L. Coote*
}

Accurate quantum chemical calculations were employed to investigate the mechanism of ozone-initiated oxidation of $\mathrm{C}-\mathrm{H}$ bonds of saturated hydrocarbons and polymers. Step wise hydrogen atom abstraction generates the first resting state the trihydroxide $-\mathrm{COOOH}$, which undergoes decomposition to produce the free radical species alkoxyl $-\mathrm{CO} \cdot$ and peroxyl $\bullet \mathrm{OOH}$ thereby setting off a complex chain of radical processes. The $\mathrm{H}$ transfer from peroxyl radical to alkoxyl allows formation of inactive alcohol and the singlet excited dioxygen. Other competitive processes include the self fragmentation or $\beta$-scission of the alkyoxyl -CO. to give rise to a carbonyl (ketone or aldehyde) and a C-centred free radical species. Tertiary $\mathrm{C}-\mathrm{H}$ bonds are most susceptible to $\mathrm{O}_{3}$ oxidation followed by secondary and primary. Among the polymers studied, poly(styrene) is the least resistant to $\mathrm{C}-\mathrm{H}$ bond ozonation, followed by poly(proplyene), poly(methacrylate), poly(methyl methacrylate) and poly(vinyl chloride). Calculations also reveal catalytic effects of water in promoting the $\mathrm{C}-\mathrm{H}$ bond oxidation process in polymer systems without competing $\mathrm{H}$-bond donor groups.

\section{Introduction}

Ozone is highly reactive and, despite its small concentration, ( 100 parts per billion volume, ppbv), plays a crucial role in atmospheric chemistry ${ }^{1,2}$. Its deleterious effects on human health $^{3,4}$, plants ${ }^{5}$ and polymers ${ }^{6}, 7$ have also been widely studied. The less reactive but more abundant oxygen is central to the basic autooxidation scheme (BAS; see Scheme 1), 8-10 playing a key role in propagating autooxidation, and in our context, polymer degradation. However, a series of experimental studies by Barner-Kowollik and co-workers ${ }^{11-14}$ on the chemical degradation of poly(methyl methacrylate) (pMMA) recently challenged the traditional view of polymer autooxidation. In addition, it is known that oxygen slows polymer autooxidation, ${ }^{15}$ and our calculations have suggested that the propagation step in BAS, hydrogen abstraction from the polymer by the peroxyl radical, is strongly thermodynamically disfavoured for most saturated polymers. ${ }^{16}$ These questions about the BAS mechanism, have prompted us to investigate the chemical relationship between polymer degradation and other stronger oxidants such as ozone. Employing accurate quantum chemical calculations, ${ }^{17}$ we have previously shown how unsaturated bonds at the polymer chain ends readily react with ozone to initiate radical species that accelerate polymer degradation (Scheme 2, top). However, these unsaturated chain ends only constitute a minor fraction of the entire polymer composition, ${ }^{18}$ while non-polar $\mathrm{C}-\mathrm{H}$ groups on the other hand are ubiquitous. Ozone has been reported to react at low to ambient temperatures with saturated hydrocarbons, ${ }^{19}, 20$ acetals, ${ }^{21}, 22$ aldehyde and ethers ${ }^{23}$. The corresponding measured rates for hydrocarbonozone $\mathrm{C}-\mathrm{H}$ oxidation decrease in the order tertiary > secondary $>$ primary. ${ }^{19,}, 20$

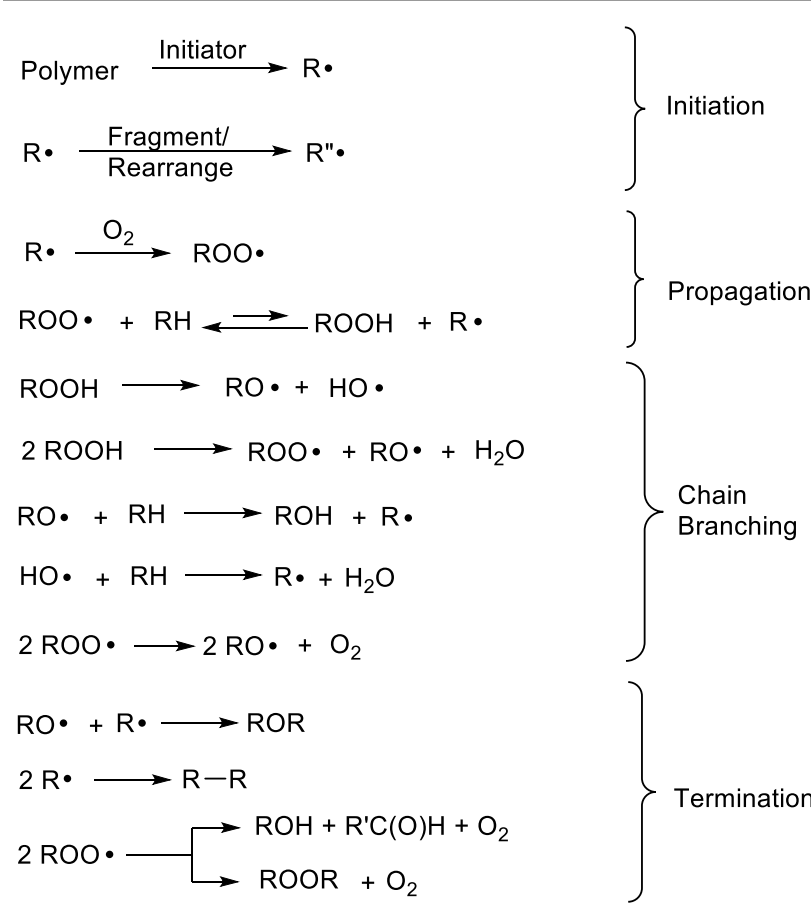

Scheme 1. Basic autooxidation scheme

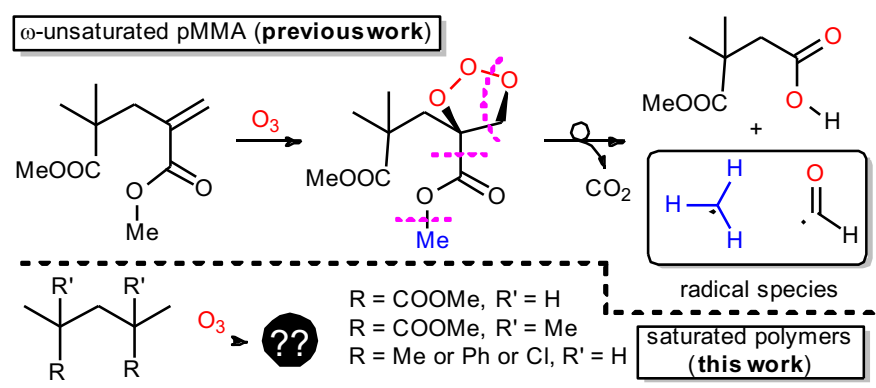

Scheme 2. Top: previous computational work ${ }^{17}$ examining $\omega$-unsaturated pMMA oxidation by $\mathrm{O}_{3}$. Bottom: current work investigating $\mathrm{C}-\mathrm{H}$ bond oxidative transformation on various polymers by $\mathrm{O}_{3}$.

The mechanism for $\mathrm{C}-\mathrm{H}$ ozonation has been proposed to occur via three possible pathways 23,24 (Scheme 3): (a) 1,3 dipolar insertion, $(b)$ step-wise radical $\mathrm{H}$-atom transfer and $(c)$ stepwise ionic hydride transfer. For pathways $b$ and $c$, recombination of the radical species or ionic pair forms the alkyl 
hydrotrioxide product. It was also rationalized that the concerted 1,3 dipolar insertion is less energetically feasible. ${ }^{24}$ Subsequently, experimental mechanistic studies on the ozonation reaction of cumenes, alcohols and dioxolane were carried out by Cremer and Plesničar, ${ }^{25-29}$ and this work, along with DFT calculations, suggests that different functional groups affect the pathway by which $\mathrm{O}_{3} \cdots \mathrm{H}$ abstraction occurs (Scheme 3). For $\mathrm{C}-\mathrm{H}$ bonds which are polarized, by for example an adjacent ether group as in dioxolane, hydride transfer is the more likely (path $c)^{27}$ while for the benzylic $\mathrm{C}-\mathrm{H}$ bond in cumeme the radical pathway $b$ was proposed ${ }^{26}$.

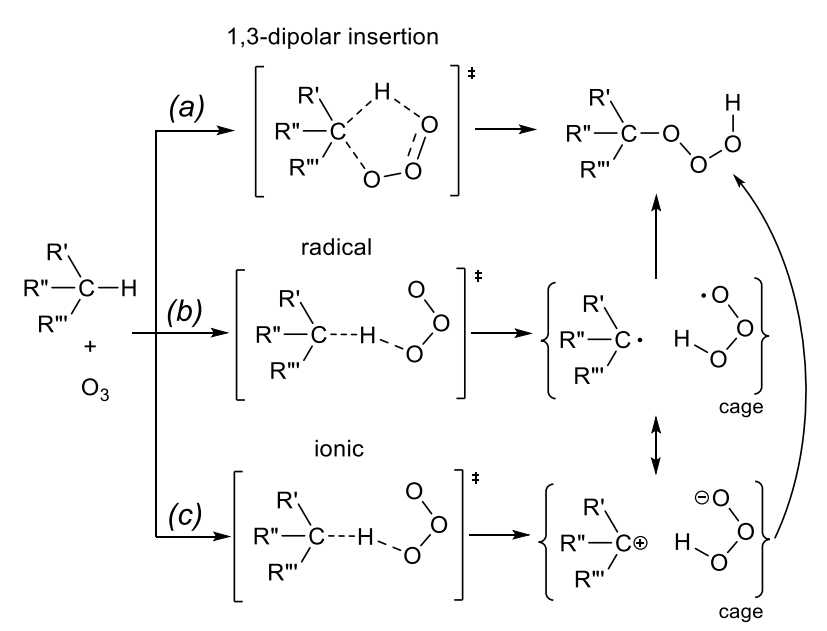

Scheme 3. Pathways for $\mathrm{O}_{3}$ oxidation of $\mathrm{C}-\mathrm{H}$ bonds

However, to date there are have been no detailed mechanistic studies of $\mathrm{O}_{3}$ initialized oxidative decomposition of non-polar saturated molecules, which are common in the structural and chemical makeup of polymers. In the present work, as continuation of our efforts to better understand polymers under the oxidative stress of environmental ozone, accurate $a b$ initio calculations were first carried out to rationalize a plausible mechanism for the ozone-initiated oxidation process of a small saturated hydrocarbon, isobutane. Subsequently, the computational study was extended to investigate larger molecules of representative polymer classes: poly(propylene) (pProp), poly(styrene) (pSty), poly(methyl acrylate) (pMA), poly(methyl methacrylate) (pMMA) and poly(vinyl chloride) (pVC) (Scheme 2, bottom), and to investigate the potential catalytic role of water in the process.

\section{Computational methods}

General methods. All calculations were carried out with the Gaussian $09^{30}$ computational suite. Geometry optimization of minimum and transition state (TS) structures were performed with Truhlar's M11 functional ${ }^{31}$ and Pople's double $\zeta$ 6$31+G(d, p)$ basis set32, 33. Electronic energies were further improved with highly-correlated techniques, the composite G4(MP2)-6X method $^{34}$ and benchmark calculations with restricted coupled cluster theory $\operatorname{CCSD}(T)^{35}$, or $\operatorname{RCCSD}(T)$ and Aldrich's triple $\zeta$ def2-TZVP basis set ${ }^{36}$ (for benchmarking see Supporting Information). Thermal and entropic corrections (at
298.15K) were calculated using the standard textbook formulae for the statistical thermodynamics of an ideal gas under the harmonic oscillator / rigid rotor approximation, and combined with G4(MP2)-6X electronic energies to obtain the Gibbs' free energies and enthalpies reported herein.

$\mathrm{O}_{3}$ Benchmarking Study. To validate the chosen method, the minimum energy electronic structure of ozone was located with both closed-shell (RM11) and broken symmetry M11 (UM11) calculations. A number of previous theoretical studies have been devoted to studying the intriguing electronic structure of $\mathrm{O}_{3}$. Early computational studies, carried out with $a b$ initio generalized valence bond and configuration interaction theory, ${ }^{37}$ suggested that the ground state $\mathrm{O}_{3}$ is a singlet biradical by nature with singly occupied $\pi$ orbitals at both 0 terminus. ${ }^{38}$ However, the biradical nature of $\mathrm{O}_{3}$ has been debated and contested in theoretical accounts ranging from suggestions that the ground state is closed-shell singlet, 39 to predictions of a $30 \%$ biradical character ${ }^{40}$. Recent theoretical studies have calculated the biradical character to be 16 or $18 \% .{ }^{41,42}$

In the present work, the broken symmetry solution located an equilibrium structure that is close to the experimental (high resolution infrared spectroscopy ${ }^{43}$ ) structure. The same DFT approach UM11 was also demonstrated to be accurate in predicting the $E_{S-T}$ of diradicals, i.e. singlet and triplet $\mathrm{O}_{2} .{ }^{44}$ Computational work carried out by Saito and co-workers on ozone 1,3 dipolar cycloaddition with ethylene and acrylonitrile showed that the single-reference wave function closed-shell $\operatorname{RCCSD}(T)$ is able to reliably describe the biradical character of ozone with an accuracy on par with the multi-reference coupled cluster method (MkCC). ${ }^{45}$ Their calculations also revealed that the single point $\operatorname{RCCSD}(\mathrm{T})$ energy of $\mathrm{O}_{3}$, based on a geometry optimized with broken symmetry DFT, is close to that of the coupled cluster energy of the experimental structure. Our calculations show similar tendencies, as the $\operatorname{RCCSD}(T)$ is able to capture the static correlation more reliably based on the $T_{1}$ diagnostic ${ }^{46}$ (Table 1). All singlet multiplicities are calculated with RCCSD(T) in the G4(MP2)-6X formalism.

Table 1. Optimization method of $\mathrm{O}_{3}$ and corresponding calculated geometrical features and electronic energies $[\mathrm{UCCSD}(\mathrm{T})$ and $\operatorname{RCCSD}(\mathrm{T}))$. The $\operatorname{CCSD}(\mathrm{T})$ energies are in hatrees. Values in parenthesis are $T_{1}$ values and in brackets are the spinsquared expectant values, $\left\langle S^{2}\right\rangle$.

\begin{tabular}{|c|c|c|c|c|}
\hline $\begin{array}{l}\text { Optimization } \\
\text { Method }\end{array}$ & $r_{e} / \AA ̊$ & $\theta /^{\circ}$ & $\operatorname{UCCSD}(T)$ & $\operatorname{RCCSD}(T)$ \\
\hline RM11 & 1.2388 & 118.03 & $\begin{array}{c}-225.1300340 \\
(0.064) \\
<0.9006>\end{array}$ & $\begin{array}{c}-225.1394686 \\
(0.025)\end{array}$ \\
\hline UM11 & 1.2606 & 116.23 & $\begin{array}{c}-225.1314363 \\
(0.062) \\
<0.9211>\end{array}$ & $\begin{array}{c}-225.1412077 \\
(0.026)\end{array}$ \\
\hline experiment $^{43}$ & $\begin{array}{r}1.27276 \\
\pm 0.00015\end{array}$ & $\begin{array}{c}116.7542 \\
\pm 0.0025\end{array}$ & $\begin{array}{c}-225.1319752 \\
(0.061) \\
<0.9360>\end{array}$ & $\begin{array}{c}-225.1419214 \\
(0.028)\end{array}$ \\
\hline
\end{tabular}




\section{Results \& Discussion}

Reaction Mechanism. As outlined above in Scheme 3, the mechanism of $\mathrm{O}_{3}$ oxidation of $\mathrm{C}-\mathrm{H}$ bonds has been proposed to occur via either a concerted 1,3-dipolar insertion mechanism (pathway $a$ ) or a step-wise process in which hydrogen is first abstracted forming either radical (pathway $b$ ) or ionic (pathway c) caged species. To discriminate these pathways for non-polar saturated systems, we first considered the reaction of $\mathrm{O}_{3}$ and $\mathrm{Me}_{3} \mathrm{CH}$ (see Figure 1 top).

In the first step of this process, a pre-complex, int-1, is formed and this reaction is slightly exothermic $(\Delta H)$ but overall endergonic $(\Delta G)$ with respect to the free starting materials. From this pre-complex, both the concerted and stepwise processes are possible, with the step-wise (hydrogen abstraction) process considerably more favoured. Not unexpectedly, $\mathrm{H}$ abstraction from the tertiary $\left(3^{\circ}\right) \mathrm{C}$ is more viable than the primary $\left(1^{\circ}\right) \mathrm{C}$. The activation enthalpy for the most energetically feasible ozonation pathway through TS1a is $\Delta H^{\ddagger}=15.3 \mathrm{kcal} / \mathrm{mol}$ and the corresponding free energy activation barrier is $\Delta G^{\ddagger}=24.9 \mathrm{kcal} / \mathrm{mol}$ with reference to the starting materials.

In a bid to understand the stability of TS1a over TS1b, TS1c and TS1d, we carried out an activation strain model analysis ${ }^{47,48}$ on the optimized TS structures (Figure 1 bottom). In this analysis, the activation barrier is decomposed into a contribution from the strain energy $\Delta E^{\ddagger}$ strain required to distort the reactants to their geometries in the transition structure, and the remaining "interaction" energy $\Delta E^{\ddagger}{ }_{i n t}$. All 4 transition structures with the exception of TS1c show unconventionally low activation strain energy $\Delta E^{\ddagger}$ strain, with TS1a having the lowest value overall, thus resulting in the lowest overall barrier.

After the first elementary $\mathrm{C}-\mathrm{H}$ bond activation step by $\mathrm{O}_{3}$, see Scheme 4, the ionic pair $t-\mathrm{Bu}^{+}$and $\mathrm{HO}_{3}{ }^{-}$(int-2(zw)) could exist in resonance with its radical pair form: $t-\mathrm{Bu} \cdot$ and $\mathrm{HO}_{3} \cdot$ (int-2(rad)). DFT calculations carried out on cyclic acetals showed that the radical pair would be more energetically favourable than the ionic pair in gas-phase by about $100 \mathrm{kcal} / \mathrm{mol}$ while in polar solvents, the ionic pair would be more stable. ${ }^{29}$ For low temperature solution-phase cumene ozonation however, the radical pair would more likely exist. ${ }^{26}$ In the context of $\mathrm{O}_{3}$ damage to polymer surfaces, it is most relevant to examine this chemistry vis-à-vis the gas-phase, and hence the radical pair form. Both int-2(zw) and int-2(rad) following the $\mathrm{C}-\mathrm{H}$ bond oxidation are endergonic, $\Delta G_{\mathrm{rxn}}=141.3$ and $15.8 \mathrm{kcal} / \mathrm{mol}$ respectively, and the process will only be driven forward if a more thermodynamically stable intermediate forms. The radical pair int-2(rad) eventually collapses via a barrierless recombination step and two possible minimum structures were found and optimized: $t$-butyl hydrotrioxide, ${ }^{49,} 50$ tbh $\left(\Delta G_{\mathrm{rxn}}=-\right.$ $36.2 \mathrm{kcal} / \mathrm{mol})$, and a meta-stable zwitterionic intermediate int$3\left(\Delta G_{\mathrm{rxn}}=-0.1 \mathrm{kcal} / \mathrm{mol}\right)$. The latter serves as an intermediate connecting to TS2b, which represents the transition state structure for the ionic proton elimination step forming hydrogen trioxide $\left(\mathrm{HO}_{3} \mathrm{H}\right)$ and isobutene.
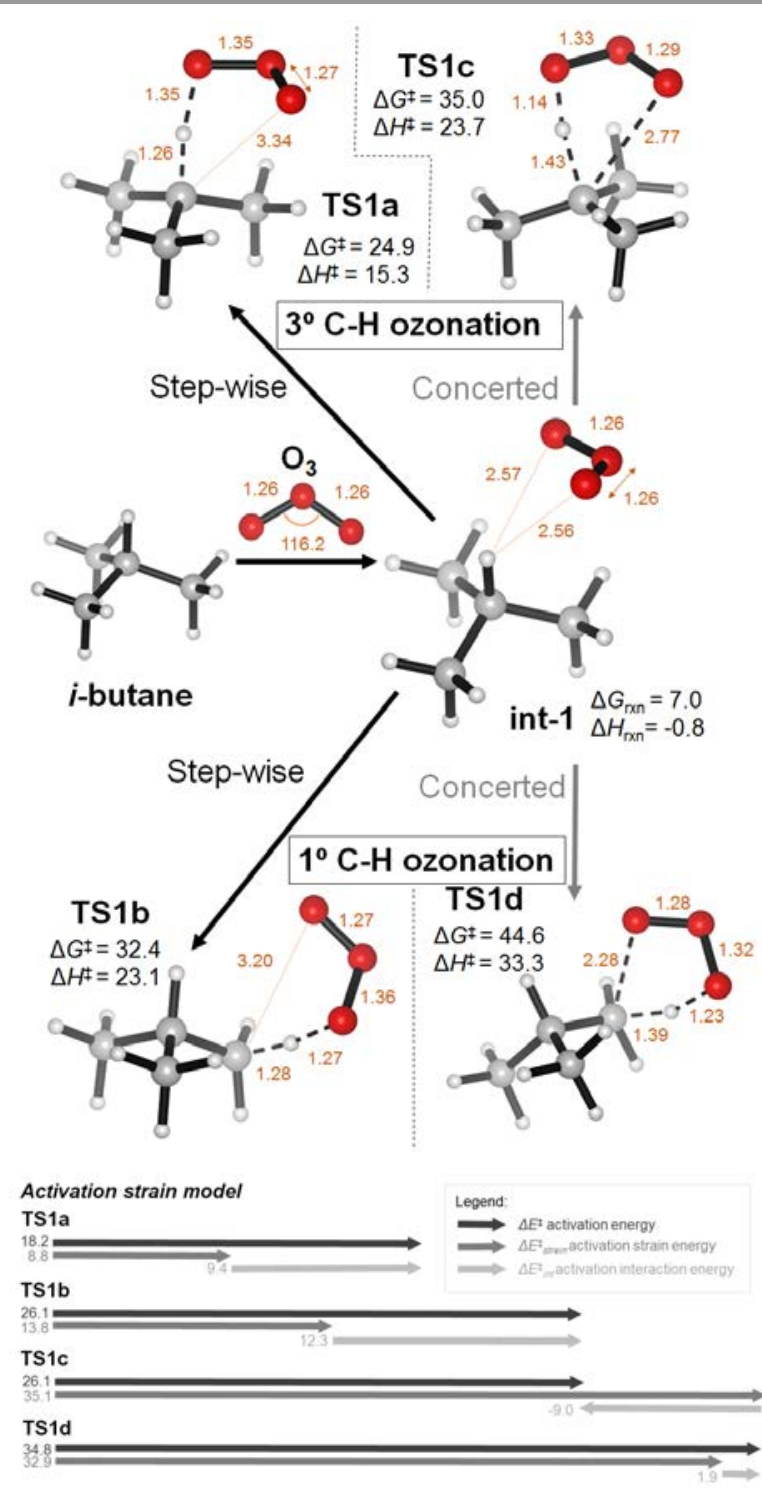

Figure 1. Top: calculated pathways for $\mathrm{O}_{3}$ oxidation of tertiary and primary $\mathrm{C}-\mathrm{H}$ bonds of representative small molecule, $i$-butane. Shown are optimized minimum and TS structures with bond distances in $\AA$, and free energy and enthalpy values analysis of TS1.

Experimental studies of the low temperature ozonation of cumene in the solution phase, vide supra, have observed the generation of $\mathrm{HO}_{3} \mathrm{H} .{ }^{26}$ This observation can be explained by the stabilization effect of solvents on the highly polarized int-3 and TS2b. In contrast, in the gas-phase, the free energy difference between int-3 and tbh is large (ca. $36 \mathrm{kcal} / \mathrm{mol}$ ), indicating that the tbh form would be predominant. The stable hydrotrioxide tbh could further undergo O-O cleavage to generate either the peroxy, i-BuOO., or alkoxy, i-BuO., O-centred radical species. With the UM11 method, a TS for the RO...OOH fragmentation process (TS2a) was located but not for the ROO...OH cleavage. Based on the free energies of the resulting radical fragments, $\mathrm{RO} \cdots \mathrm{OOH}$ fragmentation (i.e. $\mathrm{i}$-BuO. $+\mathrm{HOO} \cdot$ ) appears to be preferred by about $3 \mathrm{kcal} / \mathrm{mol}$ compared to $i$-BuOO + HO. The free energy activation barrier for this $\mathrm{O}-\mathrm{O}$ homolytic process TS2a is feasible at ambient conditions $\left(\Delta G^{\ddagger}=19.0 \mathrm{kcal} / \mathrm{mol}\right.$ relative to tbh). Our calculated kinetic parameters for the 
$\mathrm{RO} \cdots \mathrm{OOH}$ homolysis are $E_{\mathrm{a}}=20.6 \mathrm{kcal} / \mathrm{mol}$ and $\log A=12.5$, which are reasonably close to the experimental values of $E_{\mathrm{a}}$ $=23.0 \pm 2.0 \mathrm{kcal} / \mathrm{mol}$ and $\log A=16.0 \pm 2.0 .26$

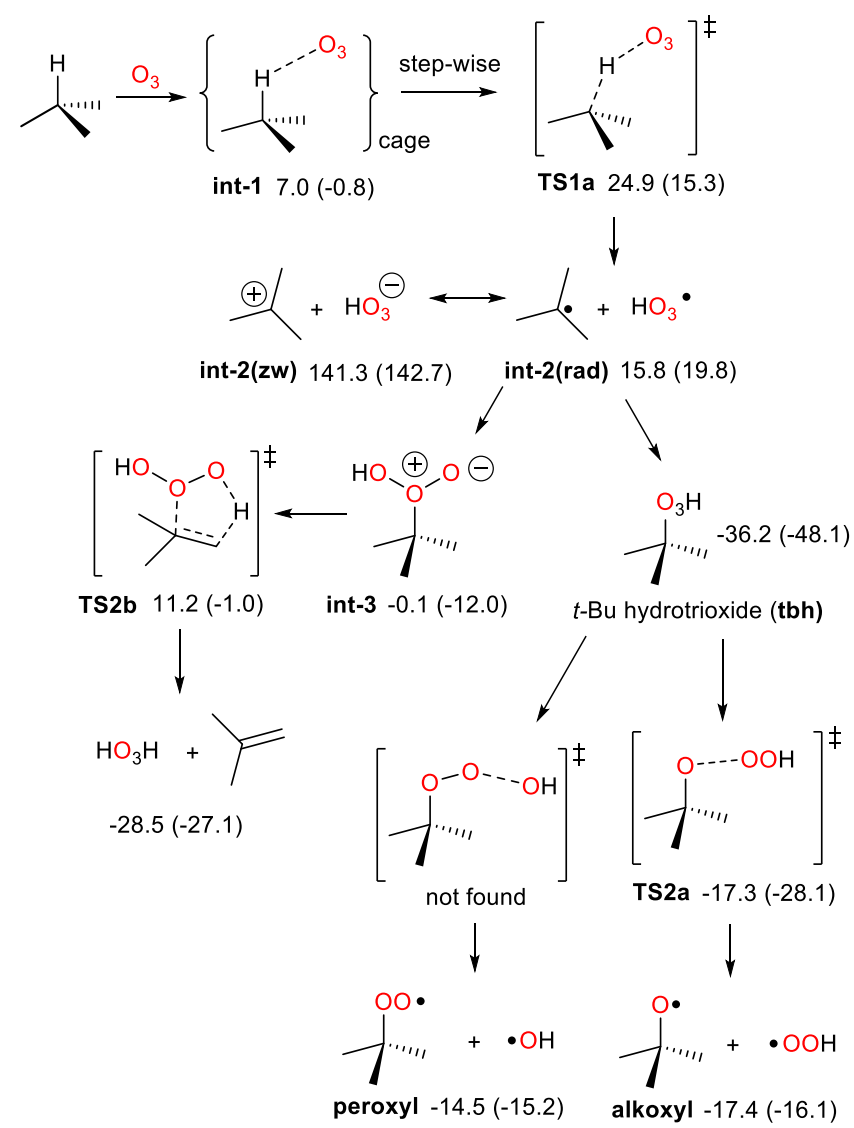

Scheme 4. Calculated pathways after first tertiary $\mathrm{C}-\mathrm{H}$ bond $\mathrm{O}_{3}$ oxidation step. Values are free energies and enthalpies (in parenthesis) in $\mathrm{kcal} / \mathrm{mol}$ with reference to starting materials $i$-butane and $\mathrm{O}_{3}$.

Reactivity of RO• and HOO•. The direct termination of alkoxyl $i$-BuO. via $\mathrm{H}$ transfer (Scheme 5 top) from HOO. produces alcohol and singlet $\mathrm{O}_{2}$. Indeed, previous studies of the ozonation of isopropyl alcohol detected singlet $\mathrm{O}_{2} \cdot{ }^{25}$ An alternative suggestion for alcohol formation is via recombination of the $i$ $\mathrm{Bu} \cdot$ radical with $\mathrm{HO}$. from the prior dissociation of $\mathrm{HO}_{3} \cdot\left(\mathrm{HO}_{3} \bullet \rightarrow\right.$ $\left.\mathrm{HO} \cdot+{ }^{1} \mathrm{O}_{2}\right) .{ }^{28,29}$ The TS (TS4a) for direct $\mathrm{H}$ transfer from the HOO. to alkoxyl was not located, but $\mathrm{H}$ transfer in the triplet channel gave TS4b with $\Delta G^{\ddagger}=24.9 \mathrm{kcal} / \mathrm{mol}$ relative to tbh (Scheme 5). Gas-phase studies have indeed confirmed that the majority of oxidation products are alcohols with significant fractions of acetone and $\mathrm{CO}_{2}$, thus indicating a complex reaction mechanism involving different oxidation pathways. ${ }^{19}$ Formation of the alcohol product could also result from the alkoxyl $i$-BuO. abstracting a tertiary $\mathrm{H}$ from another isobutane molecule (TS4c $\Delta G^{\ddagger}=32.0 \mathrm{kcal} / \mathrm{mol}$ relative to tbh). Ketone formation occurs via $\beta$-scission, ${ }^{19}$ and this fragmentation process (TS3) has a slightly lower free energy barrier than TS4a $\left(\Delta G^{\ddagger}=24.3 \mathrm{kcal} / \mathrm{mol}\right.$ relative to tbh).

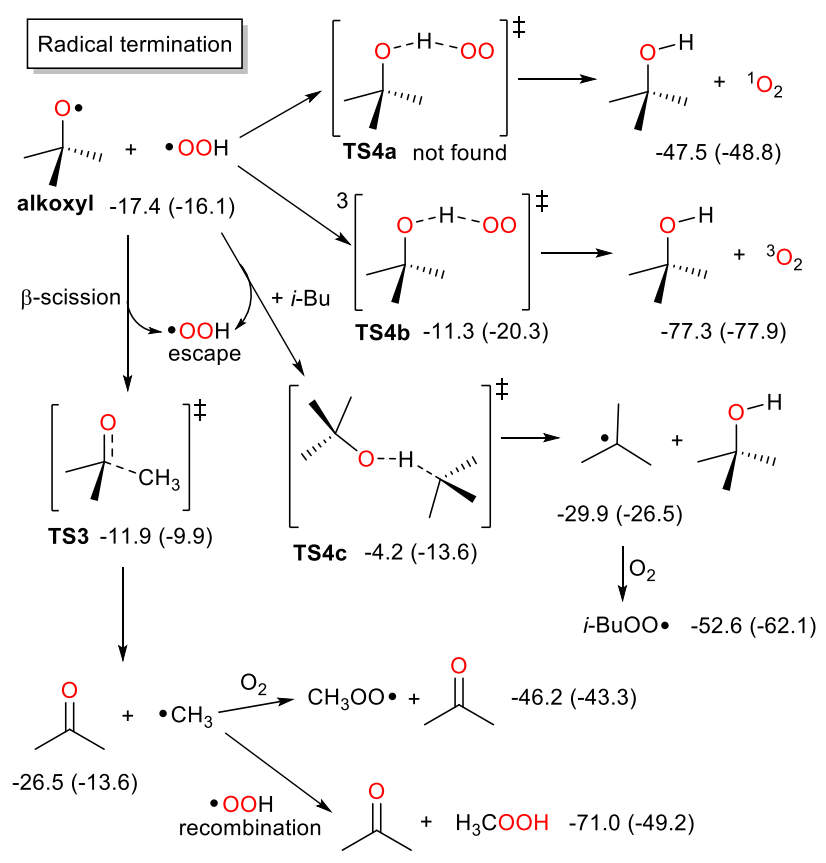

Scheme 5. Calculated pathways for further decomposition of alkoxyl and peroxyl radicals generated from thh. Values are free energies and enthalpies (in parenthesis) in $\mathrm{kcal} / \mathrm{mol}$ with reference to $i$-butane and $\mathrm{O}_{3}$.

Decomposition of tbh would thus be driven by the thermodynamic stability of the inert products, but the relative amounts of oxidized terminal products formed could further be complicated by additives, such as acetone, ethyl acetate or acetonitrile, which would favour carbonyls rather than alcohols as termination products. ${ }^{51}$ Polymers with these as side-chain functional groups (eg. acrylates) could more likely undergo $\beta$ scission, concomitantly regenerating the alkyl free radical species. These alkyl radicals would be further oxidized by ${ }^{3} \mathrm{O}_{2}$ to form more stable peroxyl radicals (Scheme 5; $\Delta G_{\mathrm{rxn}}=-19.7$ $\mathrm{kcal} / \mathrm{mol})$, key intermediates in the autooxidation cycle (Scheme 1). Indeed, experimental studies using $\mathrm{O}_{3}$ for surface modification of polymers, 52 such as poly(propylene), 53,54 have identified a variety of oxygenated or unsaturated functional groups (olefinic $\mathrm{C}=\mathrm{C}$, hydroxyl, carbonyls, esters, $\mathrm{y}$-lactones, and $\mathrm{H}$-bonded hydroxyl and hydroperoxide groups). Furthermore, IR studies have revealed that oxidation reactions 


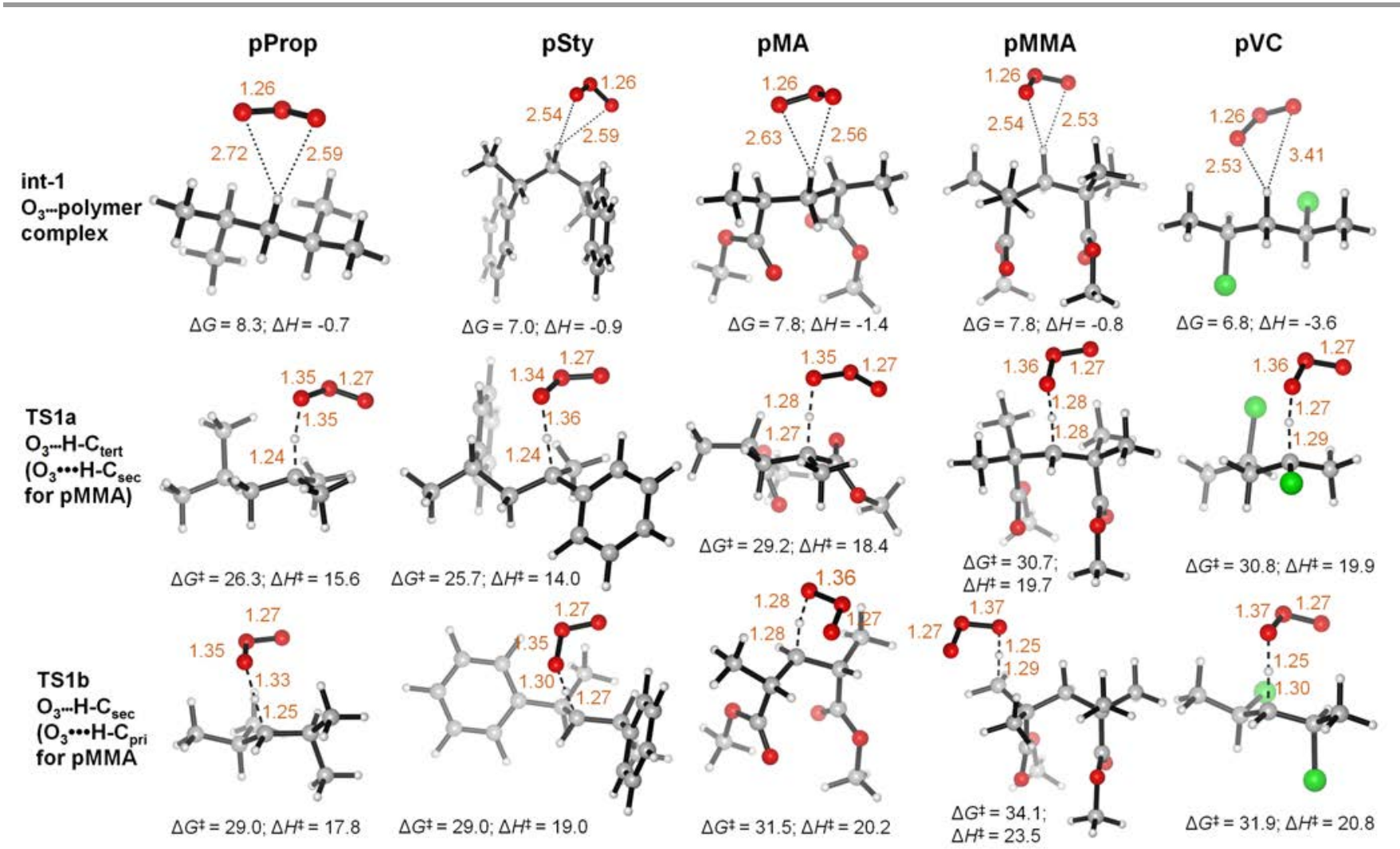

Figure 2. Calculated pathways for $\mathrm{O}_{3}$ oxidation of tertiary, secondary or primary C-H bonds of representative polymer dimers: pProp, pSty, pMA, pMMA and pVC. Shown are optimized minimum and TS structures with bond distances in $\AA$, and free energy and enthalpy values in $\mathrm{kcal} / \mathrm{mol}$ with reference to free starting materials.

occur not only on the exposed surface but in the depth of material as well. All these observations directly point to a chain of free radical reactions operating to form various inactive products or defect structures initiated by $\mathrm{O}_{3}$ oxidation.

Polymer ozonation. Having established the basic mechanism, we expanded our modelling to include representative polymer dimer units. TS structures for the first elementary $\mathrm{O}_{3} \cdots \mathrm{H}$ abstraction step of ozone-initiated $\mathrm{C}-\mathrm{H}$ bond oxidation were optimized for models of the polymers of propylene (pProp), styrene (pSty), methylacrylate (pMA), methyl methacrylate (pMMA) and vinyl chloride ( $\mathrm{pVC}$ ) (see Fig. 2). Oxidation of tertiary $\mathrm{C}-\mathrm{H}$ bond sites is most facile followed by secondary and then primary. For tertiary carbon $\mathrm{H}$ abstraction (or secondary in the case of pMMA as it has no tertiary $\mathrm{C}-\mathrm{H}$ bonds) the free energy of activation relative to starting materials $\left(\Delta G^{\ddagger}\right.$ in $\mathrm{kcal} / \mathrm{mol}$ ) increases in order: pSty (25.7) > pProp (26.3) > pMA (29.2) > pMMA (30.7) $\approx$ pVC (30.8). Relative to reactants, the pProp free energy barrier is higher than for $i$-butane $\left(\Delta G^{\ddagger}=26.3\right.$ vs $24.9 \mathrm{kcal} / \mathrm{mol})$. However, relative to the $\mathrm{O}_{3} \cdots$ polymer complex or int-1, both pProp and $i$-butane will have nearly identical barriers as expected. Based on the reaction enthalpies, binding of $\mathrm{O}_{3}$ to polymers results in slightly exothermic complexes (int-1) in the range of $\Delta H=-0.7$ to $-3.6 \mathrm{kcal} / \mathrm{mol}$. The TS1a activation enthalpies $\left(\Delta H^{\ddagger}\right.$ values in $\mathrm{kcal} / \mathrm{mol}$ relative to int-1) follow a similar trend: pSty (14.9) > pProp (16.3) > pMA (19.8) > pMMA (20.5) > pVC (23.5). Taken together, and ignoring the potential impact of unsaturated defect structures, the polymers $\mathrm{pMA}, \mathrm{pMMA}$ and $\mathrm{pVC}$ demonstrate stronger resistance to $\mathrm{C}-\mathrm{H}$ oxidation by $\mathrm{O}_{3}$.
Scheme 6 shows the reactions that occur after $\mathrm{C}-\mathrm{H}$ abstraction via TS1a, with their accompanying energetics in Table 2 . The polymer with most stable int-2(rad) fragment is pSty. This is due to the delocalization of the C-centred radical into the phenyl ring. Recombination of radicals $\mathrm{HO}_{3}$. and int-2(rad) forms the highly exoergic hydrotrioxide intermediate as the first resting state. However, further $\mathrm{O}-\mathrm{OOH}$ bond homolysis through TS2a to furnish alkoxyl and HOO. is facile. The corresponding free energy barriers increase in order pMMA (12.8) < pVC (14.8) < pSty (15.2) < pMA (16.0) < pProp (18.3). Peroxyl and alkoxyl radical species generated from homolytic TS2a processes are overall more endoergic than hydrotrioxide. For pVC however the free energies of formed peroxyl and alkoxyl are even higher than TS2a. This could be due to the fact that as $\mathrm{O}-\mathrm{OOH}$ bond breaks, $\mathrm{Cl}$. simultaneously dissociates (Scheme 7). Indeed, the cage complex between acetone and $\mathrm{Cl}$. is much lower in free energy than the preceding alkoxyl intermediate by approximately $16.2 \mathrm{kcal} / \mathrm{mol}$. 


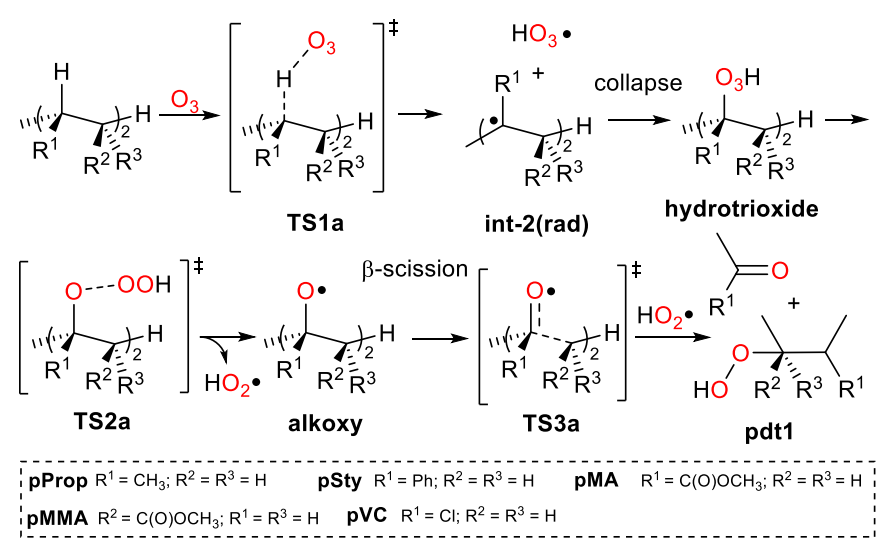

Scheme 6. Reaction pathways after the first $\mathrm{C}-\mathrm{H}$ bond $\mathrm{O}_{3}$ oxidation step for the various polymers

Table 2. Calculated barriers and reaction energies for the reactions in Scheme 6 . Values are free energies in $\mathrm{kcal} / \mathrm{mol}$ with reference to free starting materials.

\begin{tabular}{lccccc}
\hline & pProp & pSty & pMA & pMMA & pVC \\
\hline TS1a & 26.3 & 25.7 & 29.2 & 30.7 & 30.8 \\
$\begin{array}{l}\text { int-2(rad) + } \\
\text { HO }_{3} \bullet\end{array}$ & 16.1 & -16.1 & 9.1 & 18.1 & 16.4 \\
hydrotrioxide & -34.0 & -30.5 & -30.1 & -25.7 & -30.1 \\
$\begin{array}{l}\text { TS2a } \\
\text { alkoxy + }\end{array}$ & -15.7 & -15.3 & -14.1 & -12.9 & -15.3 \\
HO & & & & & \\
TS3a & -16.9 & -17.0 & -22.3 & -15.3 & -7.1 \\
pdt1 & -13.8 & -18.0 & -13.8 & -11.3 & -- \\
\hline
\end{tabular}

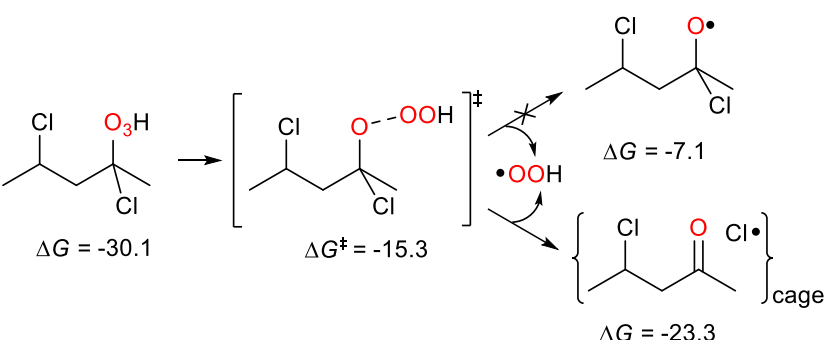

Scheme 7. Simultaneous dissociation of $\mathrm{Cl}$. during $\mathrm{O}-\mathrm{O}$ bond dissociation. Free energies in $\mathrm{kcal} / \mathrm{mol}$ relative to starting materials.

Further fragmentation of the alkoxyls through $\beta$-scission (TS3a) and recombination of $\mathrm{HOO}$. and the $\mathrm{C}$-centred radical fragment leads to highly energetically stable ketone and hydroperoxide products. The TS3a free energy barriers calculated in reference to the hydrotrioxides are higher than TS2a with the exception of pSty: $\Delta G^{\ddagger}{ }_{\text {prop }}=20.2, \Delta G^{\ddagger}{ }_{\mathrm{pSty}}=12.5, \Delta G^{\ddagger}{ }_{\mathrm{pMA}}=16.7$, and $\Delta G^{\ddagger}{ }_{\mathrm{pMMA}}$ $=14.4 \mathrm{kcal} / \mathrm{mol}$.

Alternative pathways. For pMA an alternative $\beta$-scission reaction could occur by eliminating the acyl group which we previously calculated to be kinetically viable, ${ }^{17}$ and indeed the barrier for this scission TS3b (Scheme 8) is lower by $0.9 \mathrm{kcal} / \mathrm{mol}$ compared to TS3a. Further decomposition of the acyl radical to
$\mathrm{CO}_{2}$ and $\mathrm{CH}_{3}$. thermodynamically drives the fragmentation process forward.

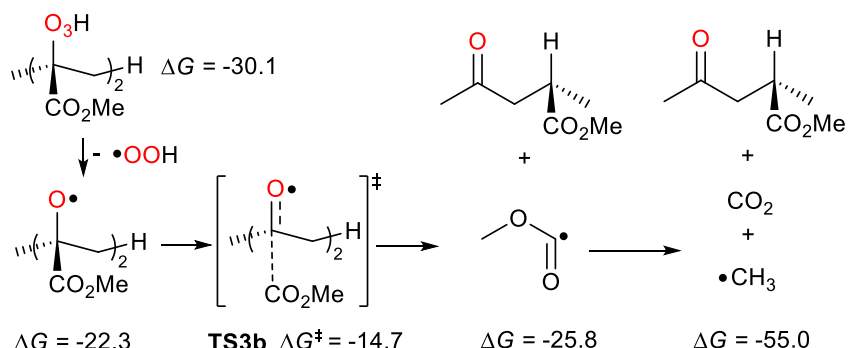

Scheme 8. Kinetically and thermodynamically favourable $\beta$-scission route for pMA producing acyl radical and subsequent decomposition. Free energies in $\mathrm{kcal} / \mathrm{mol}$ relative to starting materials.

We also considered intramolecular RO $\ldots \mathrm{H}$ abstraction by the alkoxyl radical for pProp (Scheme 9). The six-membered cyclic TS4 (1,5) is lower in energy by $\sim 5 \mathrm{kcal} / \mathrm{mol}$ relative to $\mathbf{T S 4}(\mathbf{1 , 4})$. However, this process is still more energetically costly overall than TS3a or TS3b.

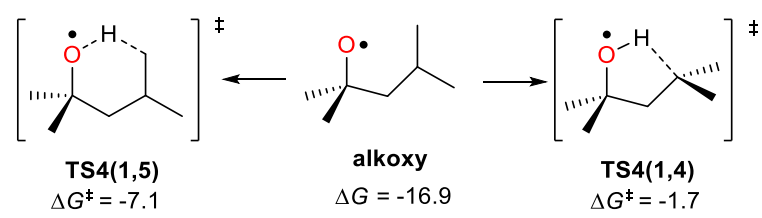

Scheme 9. Intramolecular $\mathrm{H}$ abstraction by - $\mathrm{CO}$. group. Free energies in $\mathrm{kcal} / \mathrm{mol}$ relative to starting materials.

The side-chain groups of polymers could also undergo ozonation. To study this effect, we probed the reaction of $\mathrm{O}_{3}$ with representative molecules of pSty and pMA (or pMMA) using cumene and a methyl isobutyrate ester respectively (Scheme 10). The 1,3 dipolar addition free energy activation barrier for $\mathrm{O}_{3}$ and the phenyl group is $27.3 \mathrm{kcal} / \mathrm{mol}$ which is much higher than typical addition to unsaturated $\mathrm{C}=\mathrm{C}$ bonds ( $15 \mathrm{kcal} / \mathrm{mol}$, see reference 17$)$ and this is due to destabilization from dearomatization of the phenyl ring. The resulting primary ozonide is exoergic by $6.3 \mathrm{kcal} / \mathrm{mol}$. Activation of the phenyl $\mathrm{C}\left(\mathrm{sp}^{2}\right)-\mathrm{H}$ bond with $\mathrm{O}_{3}$ (step-wise and concerted) were also calculated and the resulting activation barriers are 8 to $12 \mathrm{kcal} / \mathrm{mol}$ higher than the 1,3 dipolar addition process. For the ester, the free energy barrier for $\mathrm{C}-\mathrm{H}$ bond ozonation is highly unfavourable $\left(\Delta G^{\ddagger}=34.5 \mathrm{kcal} / \mathrm{mol}\right)$, so the oxidation of the side-chain group for pMA and pMMA is highly unlikely.

Summing up, alternative pathways for alkoxyl self-degradation through intramolecular RO $\cdots \mathrm{H}$ abstraction or reaction with sidechain groups are not as kinetically competitive as the $\beta$-scission process, for which the formation of the very thermodynamically stable acetone and hydroperoxide products drives the reaction forward. 

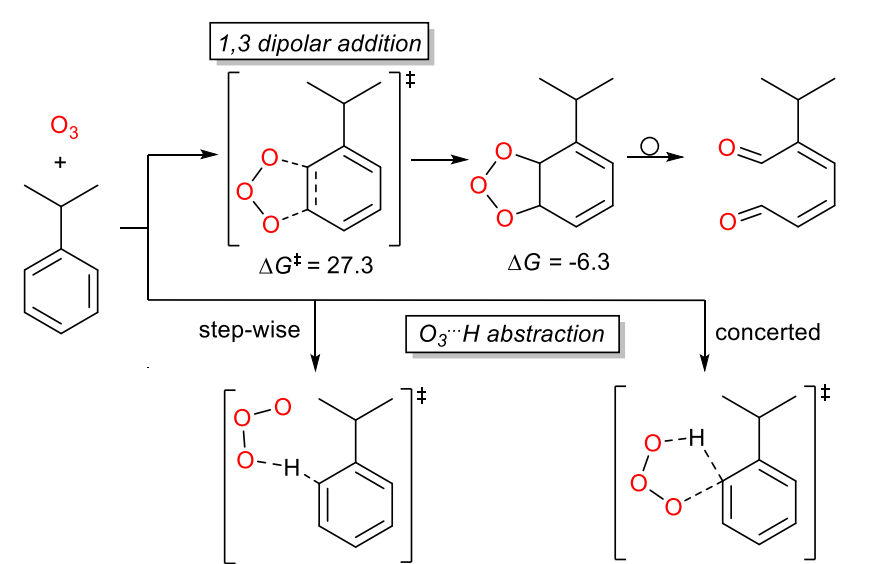

$\Delta G^{\ddagger}=39.4$

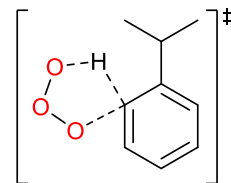

$\Delta G^{\ddagger}=35.3$

$\overbrace{O}^{O_{3}}[\overbrace{\Delta G^{\ddagger}=34.5}$

Scheme 10. Reactivity of side-chain groups: phenyl and ester. Values are free energies in $\mathrm{kcal} / \mathrm{mol}$.

Kinetic Relevance. Whilst this study shows that $\mathrm{C}-\mathrm{H}$ oxidation via ozone is a facile process, it is pertinent to consider whether or not it is kinetically relevant at atmospheric ozone concentrations. In order to have a qualitative evaluation of the magnitude of this $\mathrm{C}-\mathrm{H}$ bond $\mathrm{O}_{3}$ oxidation process, effective rates of $\mathrm{O}_{3}$ and $\mathrm{O}_{2}$ degradation on pMMA were compared. The activation energy for pMMA thermal degradation in air from experimental kinetics was reported to be $52.6 \mathrm{kcal} / \mathrm{mol}^{15}$ and the rate determining $\mathrm{O}_{3} \cdots \mathrm{H}$ abstraction process from our calculation is $21.7 \mathrm{kcal} / \mathrm{mol}$ with respect to int-1. The concentration of atmospheric $\mathrm{O}_{3}$ is assumed to be 100 parts per billion volume (ppbv) and $\mathrm{O}_{2}$ to be $2.1 \cdot 10^{8} \mathrm{ppbv}$. The ratio of effective rates i.e. $k_{\text {ozone }}\left[\mathrm{O}_{3}\right] / k_{\text {air }}\left[\mathrm{O}_{2}\right]$ is thus $2.2 \cdot 10^{16}$ or 16 orders of magnitude faster, thus highlighting the competitiveness of $\mathrm{O}_{3}$ C-H oxidation.

Water catalysis. It was reported that water catalyse hemiortho ester hydrotrioxide decomposition to the ester product through involvement in a concerted rearrangement process. ${ }^{29}$ In light of this we examined whether $\mathrm{H}_{2} \mathrm{O}$ could help promote the $\mathrm{O}_{3} \cdots \mathrm{H}$ abstraction process and modelled the reaction with water complexed ozone $\left(\mathrm{H}_{2} \mathrm{O}-\mathrm{O}_{3}\right)$ towards oxidation of isobutane, cumene and an ester (Table 4). The calculated free energy barrier for the water assisted $\mathrm{O}_{3}$ oxidation in the case of isobutane and cumene show significant lowering (by ca. 2 $\mathrm{kcal} / \mathrm{mol}$ ) compared with the unassisted oxidation while for the ester it is essentially unaffected.

In order to exact a qualitative understanding of water catalysis for isobutane and cumene, we examined the $\mathrm{H}$-bond contacts of $\mathrm{O}_{3} \cdots \mathrm{H}-\mathrm{OH}$ in the TS of the three species (Fig. 3). For isobutane and cumene, the TS1aw transition state $\mathrm{H}$ bonding distance is $2.06 \AA$, which is shortened significantly from the $2.4 \AA$ in their respective caged complex (int-1w). For the ester however, the

TS1aw shows $\mathrm{H}_{2} \mathrm{O}$ binding closer to the carbonyl $\mathrm{C}=\mathrm{O}(1.96 \AA)$ rather than to $\mathrm{O}_{3}(2.47 \AA)$. The TS1a or TS1aw $\mathrm{H}$ abstraction process formally involves hydride transfer to the $\mathrm{O}_{3}$ electrophile so having a Lewis acid $\mathrm{H}_{2} \mathrm{O}$ bound to $\mathrm{O}_{3}$ would enhance its electrophilicity.

Table 4. Calculated free energy activation barrier for $\mathrm{H}_{2} \mathrm{O}-\mathrm{O}_{3}$ (water assisted) and $\mathrm{O}_{3}$ (unassisted) oxidation of representative units of pProp, pSty and pMA with reference to int-1w (assisted) or int-1 (unassisted). Shown are optimized minimum complex int-1w and TS structures with bond distances in $\AA$.

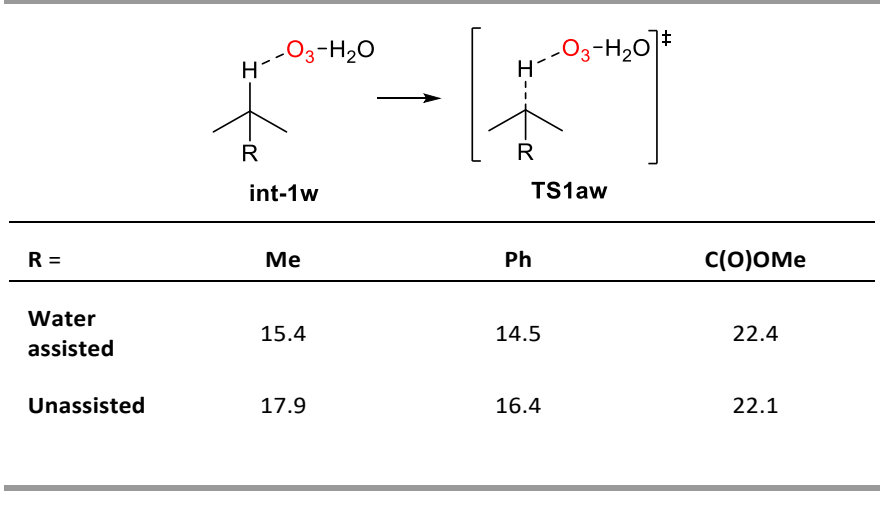

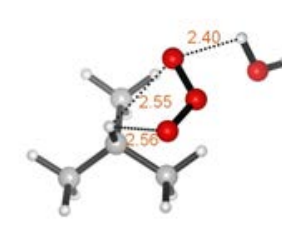

int1-w $R=M e$

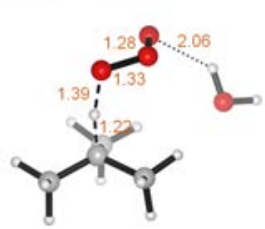

TS1aw $R=$ Me

Figure 3. Truncated molecules for pProp, pSty and pMA to study reactivity of wate assisted $\mathrm{O}_{3} \cdots \mathrm{H}$ abstraction process. Shown are optimized geometries of minimum int-1w and transition state TS1aw of the water assisted reaction. Values refer to bond distances in $\AA$.

\section{Conclusions}

Ozone reactivity as previously modelled for defective $\mathrm{PMMA},{ }^{17}$ was shown to be highly effective in initializing $\mathrm{C}=\mathrm{C}$ bond oxidative cleavage and self-propagating radical species that contribute to polymer degradation. Our calculations here demonstrate that even polymers without unsaturated bonds can also readily undergo ozone oxidation to generate radical components. Based on our modelling, the initial C-H oxidation by ozone first forms a relatively stable hydrotrioxide, which can undergo further decomposition and self-fragmentation to generate radicals that that would participate in autooxidation. The primary products from the multi-step oxidationdecomposition process identified in this study, i.e. alcohols and carbonyls, have been experimentally observed. Other classes of products generated (olefins, esters, lactones and 
hydroperoxides) are due to complex secondary radical processes for which a dynamical model is required for further studies. Finally, we discovered that atmospheric water could help catalyse the $\mathrm{O}_{3}$ oxidation process in polymer systems without competing $\mathrm{H}$-bond donors like carbonyl groups, by enhancing the electrophilicity of $\mathrm{O}_{3}$ via hydrogen bonding.

\section{Acknowledgements}

We gratefully acknowledge generous allocations of supercomputing time on the National Facility of the National Computational Infrastructure (NCl), and financial support from the Australian Research Council (ARC). We also thank Dr. Rika Kobayashi from $\mathrm{NCl}$ for advice on the $\operatorname{CCSD}(\mathrm{T})$ calculations.

\section{Notes and references}

1. R. Atkinson and J. Arey, Atoms. Environ., 2003, 37, S197S219.

2. J. D. and G. Marston, Chem. Soc. Rev., 2008, 37, 699-716

3. P. Wentworth Jr., J. E. McDunn, A. D. Wentworth, C. Takeuchi, J. Nieva, T. Jones, C. Bautista, J. M. Ruedi, A. Gutierrez, K. D. Janda, B. M. Babior, A. Eschenmoser and R. A. Lerner, Science, 2002, 298, 2195-2199.

4. P. Wentworth Jr., J. Nieva, C. Takeuchi, R. Galve, A. D. Wentworth, R. B. Dilley, G. A. DeLaria, A. Saven, B. M. Babior, K. D. Janda, A. Eschenmoser and R. A. Lerner, Science, 2003, 302, 1053-1056.

5. G. S. Taylor and S. Rich, Science, 1962, 135, 928.

6 J. S. Rugg, Anal. Chem., 1952, 24, 818-821.

$7 . \quad$ H. L. Fisher, Chem. Rev., 1930, 7, 51-138.

8. J. L. Bolland and G. Gee, Trans. Faraday Soc., 1946, 42, 244252

9. J. L. Bolland and G. Gee, Trans. Faraday Soc., 1946, 42, 236243

10 J. L. Bolland, Proc. R. Soc. London, Ser. A, 1946, 186, 218236.

11. F. Bennet, T. M. Lovestead, P. J. Barker, T. P. Davis, M. H. Stenzel and C. Barner-Kowollik, Macromol. Rapid Commun., 2007, 28, 1593-1600.

12. F. Bennet, P. J. Barker, T. P. Davis, A. H. Soeriyadi and C. Barner-Kowollik, Macromol. Chem. Phys., 2010, 211, 20342052.

13. F. Bennet, G. Hart-Smith, T. Gruendling, T. P. Davis, P. J. Barker and C. Barner-Kowollik, Macromol. Chem. Phys., 2010, 211, 1083-1097.

14. A. H. Soeriyadi, F. Bennet, M. R. Whittaker, P. J. Barker, C. Barner-Kowollik and T. P. Davis, J. Poylm. Sci. Part A: Polym. Chem., 2010, 49, 848-861.

15. J. D. Peterson, S. Vyazovkin and C. A. Wight, J. Phys. Chem. B, 1999, 103, 8087-8092.

16. G. Gryn'ova, J. L. Hodgson and M. L. Coote, Org. Biomol. Chem., 2011, 9, 480-490.

17. R. Lee and M. L. Coote, Phys. Chem. Chem. Phys., 2013, 15, 16428-16431.

18. T. Kashiwagi, A. Inaba, J. E. Brown, K. Hatada, T. Kitayama and E. Masuda, Macromolecules, 1986, 19, 2160-2168.

19. C. C. Schubert, S. J. Schubert and R. N. Pease, J. Am. Chem. Soc., 1956, 78, 2044-2048.
20. D. G. Williamson and R. J. Cvetanovic, J. Am. Chem. Soc., 1970, 92, 2949-2952.

21. P. Deslongchamps, C. Moreau, D. Fréhel and R. Chênevert, Can. J. Chem., 1975, 53, 1204-1211.

22. R. J. Taillefer, S. E. Thomas, Y. Nadeau, S. Fliszár and H. Henry, Can. J. Chem., 1980, 58, 1138-1143.

23. D. H. Giamalva, D. F. Church and W. A. Pryor, J. Am. Chem. Soc., 1986, 108, 7678-7681.

24. P. S. Nangia and S. W. Benson, J. Am. Chem. Soc., 1980, 102, 3105-3115.

25. B. Plesničar, J. Cerkovnik, T. Tekavec and J. Koller, J. Am. Chem. Soc. , 1998, 120, 8005-8006.

26. J. Cerkovnik, E. Eržen, J. Koller and B. Plesničar, J. Am. Chem. Soc., 2002, 124, 404-409.

27. B. Plesničar, J. Cerkovnik, T. Tuttle, E. Kraka and D. Cremer, J. Am. Chem. Soc., 2002, 124, 11260-11261.

28. A. Wu, D. Cremer and B. Plesničar, J. Am. Chem. Soc., 2003, 125, 9395-9402.

29. T. Tuttle, J. Cerkovnik, B. Plesničar and D. Cremer, J. Am. Chem. Soc., 2004, 126, 16093-16104.

30. Gaussian 09, Revision E.01, M. J. Frisch, G. W. Trucks, H. B. Schlegel, G. E. Scuseria, M. A. Robb, J. R. Cheeseman, G. Scalmani, V. Barone, B. Mennucci, G. A. Petersson, H. Nakatsuji, M. Caricato, X. Li, H. P. Hratchian, A. F. Izmaylov, J. Bloino, G. Zheng, J. L. Sonnenberg, M. Hada, M. Ehara, K. Toyota, R. Fukuda, J. Hasegawa, M. Ishida, T. Nakajima, Y. Honda, O. Kitao, H. Nakai, T. Vreven, J. Montgomery, J. A. , J. E. Peralta, F. Ogliaro, M. Bearpark, J. J. Heyd, E. Brothers, K. N. Kudin, V. N. Staroverov, R. Kobayashi, J. Normand, K. Raghavachari, A. Rendell, J. C. Burant, S. S. Iyengar, J. Tomasi, M. Cossi, N. Rega, J. M. Millam, M. Klene, J. E. Knox, J. B. Cross, V. Bakken, C. Adamo, J. Jaramillo, R. Gomperts, R. E. Stratmann, O. Yazyev, A. J. Austin, R. Cammi, C. Pomelli, J. W. Ochterski, R. L. Martin, K. Morokuma, V. G. Zakrzewski, G. A. Voth, P. Salvador, J. J. Dannenberg, S. Dapprich, A. D. Daniels, Ö. Farkas, J. B. Foresman, J. V. Ortiz, J. Cioslowski and D. J. Fox, Gaussian Inc., Wallingford CT, 2009.

31. R. Peverati and D. G. Truhlar, J. Phys. Chem. Lett., 2011, 2, 2810-2817.

32. R. Ditchfield, W. J. Hehre and J. A. Pople, J. Chem. Phys., 1971, 54, 724-728.

33. W. J. Hehre, R. Ditchfield and J. A. Pople, J. Chem. Phys., 1972, 56, 2257-2261.

34. B. Chan, J. Deng and L. Radom, J. Chem. Theory Comput., 2011, 7, 112-120.

35. R. J. Bartlett and M. Musial, Rev. Mod. Phys., 2007, 79, 291352.

36. F. Weigend and R. Ahlrichs, Phys. Chem. Chem. Phys. , 2005, 7, 3297-3305.

37. W. A. Goddard III, T. H. Dunning Jr, W. J. Hunt and J. P. Hay, Acc. Chem. Res., 1973, 6, 368-376.

38. J. P. Hay, T. H. Dunning Jr and W. A. Goddard III, J. Chem. Phys., 1975, 62, 3912-3924.

39. A. Kalemos and A. Mavridis, J. Chem. Phys., 2008, 129, 054312-054318.

40. E. F. Hayes and A. K. Q. Siu, J. Am. Chem. Soc., 1971, 93, 2090-2091.

41. E. Miliordos and S. S. Xantheas, J. Am. Chem. Soc. , 2014, 136, 2808-2817.

42. T. Y. Takeshita, B. A. Lindquist and T. H. Dunning Jr, J. Phys. Chem. A, 2015, 119, 7683-7694. 
43. V. G. Tyuterev, S. Tashkun, P. Jensen, A. Barbe and T. Cours, J. Mol. Spectrosc., 1999, 198, 57-76.

44. R. Lee and M. L. Coote, Aust. J. Chem., 2016 in press: dx.doi.org/10.1071/CH16093.

45. T. Saito, S. Nishihara, Y. Kataoka, Y. Nakanishi, Y. Kitagawa, T. Kawakami, S. Yamanaka, M. Okumura and K. Yamaguchi, J. Phys. Chem. A, 2010, 114, 12116-12123.

46. T. J. Lee and P. R. Taylor, Int. J. Quantum Chem., Quant. Chem. Symp., 1989, S23, 199-207.

47. W.-J. van Zeist and F. M. Bickelhaupt, Org. Biomol. Chem., 2010, 8, 3118-3127.

48. F. M. Bickelhaupt, J. Comput. Chem., 1999, 20, 114-128.

49. F. Kovač and B. Plesničar, J. Chem. Soc., Chem. Commun., 1978, 122-124.

50. F. Kovač and B. Plesničar, J. Am. Chem. Soc., 1978, 101, 2677-2681.

51. T. M. Hellman and G. A. Hamilton, J. Am. Chem. Soc., 1974, 96, 1530-1535.

52. J. J. Robin, Adv. Polym. Sci., 2004, 167, 35-79.

53. R. Oueslati and H. Bahri, Eur. Polym. J., 1992, 28, 12471252.

54. R. Oueslati and B. Catoire, Eur. Polym. J., 1991, 27, 331-340. 